\title{
O brincar de crianças com deficiência física sob a perspectiva dos pais ${ }^{1}$
}

\author{
Daniele da Silva Souza ${ }^{a}$, Brenda Antunes de Figueiredo ${ }^{a}$, Ângela Cristina Dornelas da Silva ${ }^{b}$ \\ ${ }^{a}$ Universidade Federal da Paraíba - UFPB, João Pessoa, PB, Brasil. \\ ${ }^{\text {b} D e p a r t a m e n t o ~ d e ~ T e r a p i a ~ O c u p a c i o n a l, ~ U n i v e r s i d a d e ~ F e d e r a l ~ d a ~ P a r a i ́ b a ~-~ U F P B, ~ J o a ̃ o ~ P e s s o a, ~ P B, ~ B r a s i l . ~}$
}

\begin{abstract}
Resumo: Introdução: Através do brincar, a criança se desenvolve e cultiva capacidades, habilidades, interesses e hábitos que poderá utilizar na vida cotidiana. Quando a criança tem deficiência física, o seu papel de brincante pode ser comprometido, prejudicando a experiência da descoberta, do controle, da criatividade e da expressão de si mesma. Objetivo: Investigar a percepção dos pais sobre o brincar no cotidiano de crianças com deficiência física. Método: Foi realizada uma pesquisa de abordagem qualitativa, na qual pais ou mães de crianças com deficiência física, assistidas na Clínica Escola de Terapia Ocupacional da Universidade Federal da Paraíba, foram questionados sobre o cotidiano de seus filhos em relação ao brincar. Um roteiro de entrevista semiestruturada foi elaborado especificamente para este estudo. Oito pais foram entrevistados. Resultados: Através da análise de conteúdo, verificou-se que os pais reconhecem que o brincar contribui para a aprendizagem e a interação social de seus filhos, e que as crianças com deficiência física apresentam restrição na atividade do brincar, pois partilham brincadeiras apenas com familiares e utilizam materiais que nem sempre favorecem o desenvolvimento sensorial. De acordo com os pais, as dificuldades no brincar são causadas pelos problemas de movimento e, por isto, eles muitas vezes "emprestam" seus corpos para viabilizar o brincar da criança. Conclusão: $\mathrm{O}$ estudo aponta a necessidade de os profissionais que acompanham as crianças com deficiência física colaborarem com os pais para a efetivação e a ampliação do repertório do brincar de seus filhos, contribuindo para a participação social e a autonomia da criança.
\end{abstract}

Palavras-chave: Brincadeiras, Desenvolvimento Infantil, Deficiência Física.

\section{The play of children with disabilities from the perspective of parents}

\begin{abstract}
Introduction: Through play, children develop, and cultivate skills, abilities, interests and habits used in everyday life. When the child has a disability this function of play can be compromised, affecting the experience of discovery, control, creativity and self-expression. Objective: To investigate the perception of parents of play in the daily lives of children with disabilities. Method: For both the father and mother of a child with a physical disability assisted at the Clinical Occupational Therapy School of the Federal University of Paraiba, qualitative research was conducted, from October to November 2014. They were asked about the daily lives of their children in terms of play. A semi-structured interview guide was specifically developed for this study. Eight parents participated in the study. Through content analysis it was found that parents recognize that play contributes to the learning and social interaction of their child; that children with disabilities have restricted activity during play, only sharing jokes with family members, and using materials that do not always favor sensory development. Results: According to parents, the difficulties during play are caused by movement problems and parents often "lend" their bodies to enable the play of the child. Conclusion: The study points to the need for professionals who accompany children with physical disabilities, collaborating with parents to facilitate and expand the play repertoire of their children, which contributes to social participation and child autonomy.
\end{abstract}

Keywords: Play and Playthings, Child Development, Physical Disability. 


\section{Introdução}

O brincar é um fenômeno complexo, cuja definição tem sido um desafio para muitos pesquisadores e teóricos, visto as divergências de conceitos apresentados na literatura. Entretanto, todos concordam que o brincar é uma atividade eminentemente infantil (REZENDE, 2008).

Segundo Silva e Pontes (2013), o brincar é um processo essencial a ser vivido durante a infância, através do qual a criança se constitui no mundo e o mundo se constitui para ela, numa relação mútua. É brincando que a criança adquire habilidades que contribuem no enfrentamento de situaçóes que se apresentam, formando, assim, as bases do comportamento adaptativo que lhe é útil durante a vida (SANDERS; SAYER; GOODALE, 1999 apud FERLAND, 2006).

Quando a criança brinca com os outros, ela experimenta a partilha, a rivalidade, a colaboração, a interaçáo e o afrontamento, aprendendo, de alguma forma, a encontrar o seu lugar, tornando-se um ser social (FERLAND, 2006).

Desta forma, o brincar é fundamental para cultivar capacidades, habilidades, interesses e hábitos de competição e cooperação necessários para a competência na vida adulta, pois, através deste, a criança desenvolve um saber-fazer experimental que poderá utilizar na vida cotidiana (REILLY, 1974 apud FERLAND, 2006).

Entretanto, este processo é influenciado por diferentes fatores. A deficiência física pode comprometer o papel de brincante da criança. As limitaçôes do movimento impedem que a criança acesse $\mathrm{o}$ ambiente de maneira ativa, prejudicando a exploraçáo do meio físico e levando a dificuldade em se envolver nas atividades pelo seu prazer sensório-motor. Estas limitaçôes impactam negativamente o desenvolvimento emocional e das relaçóes sociais (LORENZINI, 2002).

As crianças podem experimentar também outros problemas ligados a seu estado, como a inexperiência para brincar com pares, a dificuldade no desenvolvimento cognitivo e a dificuldade para expressar as emoçóes. Além disso, a criança com deficiência física tem menos oportunidade para brincar do que a criança "normal", porque tem menos parceiros e porque seu tempo é monopolizado pelas terapias (FERLAND, 2006).

Nestas perspectivas, a criança com deficiência física vivencia de forma diferenciada o brincar, e, consequentemente, a experiência da descoberta, do controle, da criatividade e da expressão de si, promovida pelo brincar, corre o risco de ser comprometida (FERLAND, 2006). Além das dificuldades relacionadas ao quadro clínico e funcional, a criança com deficiência física também enfrenta fatores ambientais (físicos e sociais) que podem comprometer o brincar (MISSUANA; POLLOCK, 1991).

Os fatores ambientais podem ser tấo ou até mais limitadores do que o próprio distúrbio. As barreiras sociais, que ocorrem como resultado da imposição dos valores e crenças dos outros, impossibilitam as crianças de estabelecerem interações sociais. Por outro lado, as barreiras físicas do ambiente diminuem ou impedem o acesso das crianças à recreação e ao lazer (LORENZINI, 2002).

Takatori et al. (2001) destacam que a criança com deficiência física se encontra no grupo de pessoas estigmatizadas, pois apresenta características distintas, imediatamente evidenciadas, que podem colocá-la na condição de desacreditada.

A aparência física diferente, os movimentos do corpo não usuais e a comunicação verbal, expressa por sons incompreensíveis, são exemplos de características que podem desviar ou absorver toda a atençáo do outro para aquilo que é o não esperado e, explicitamente, diferente, não restando olhar para outros atributos que as crianças com deficiência possam ter. Às vezes, não raras, os atributos relativos ao estigma parecem se manifestar em outras características que nem são da pessoa (TAKATORI et al., 2001).

Neste sentido, promover o brincar é importante para aproximar a criança com deficiência do seu meio, pois facilita a interaçấo social, possibilitando que a criança não seja vista como incapaz. A deficiência não determina a incapacidade $\mathrm{e}$, por isso, a pessoa com deficiência deve interagir com o seu meio, no qual irá imprimir a sua marca pessoal, mostrando-se singular e estabelecendo relaçôes por meio de suas experiências (TAKATORI, 2003).

Independentemente das limitaçóes que a criança com deficiência física apresente, o brincar permite que ela desenvolva o conhecimento do mundo ao seu redor e uma atitude positiva frente à ação e às habilidades nas diferentes esferas, levando em conta tanto as forças como as fraquezas das crianças (FERLAND, 2006).

Zaguini et al. (2012) destacam que a atividade do brincar deve ser graduada, possibilitando que a criança com deficiência física vivencie e exponha seus sentimentos através da experiência lúdica. É essencial dar oportunidades de participação nas brincadeiras, facilitando o contato com outras pessoas, bem como com os objetos, fora e dentro do 
convívio familiar, favorecendo o desenvolvimento e o crescimento da criança.

Rose e Gil (2003) ressaltam que tornar-se capaz de brincar envolve a aquisição de competências que parecem abrir um amplo espectro de possibilidades em adquirir e refinar capacidades e habilidades sociais, analisadas na forma do controle instrucional presente na brincadeira conjunta. Dessa forma, pode-se pensar que a criança com deficiência, além de ser incentivada a brincar, deve ter a oportunidade de acreditar que é capaz, dentro de suas potencialidades e capacidades, de construir um mundo de imaginação e diversão.

Segundo Ferland (2006), a criança deve ter a possibilidade de decidir com o que quer brincar, o que quer fazer e qual brinquedo vai utilizar para isso. Isto significa que a autonomia não se refere apenas às habilidades físicas, pois uma criança com deficiência física pode ser autônoma na medida em que avalia situações, faz escolhas e toma decisões. O brincar promove o desenvolvimento dessas capacidades.

Tendo em vista a importância do brincar para o desenvolvimento infantil e que as crianças com deficiência física apresentam limitaçôes para participar efetivamente do brincar, este estudo objetivou investigar a percepção dos pais sobre o brincar no cotidiano de crianças com deficiência física.

A literatura que aborda a importância do brincar na percepção dos pais é escassa, justificando a necessidade de estudos que abranjam a temática, reconhecendo a relevância dos discursos e das experiências dos mesmos junto a essas crianças.

\section{Método}

Trata-se de um estudo exploratório de abordagem qualitativa, realizado com pais de crianças com deficiência física, com idades entre zero e 12 anos, acompanhadas no serviço de terapia ocupacional, na Clínica Escola de Terapia Ocupacional da Universidade Federal da Paraíba, no período de outubro a novembro de 2014.

Os sujeitos da pesquisa foram identificados através dos prontuários das crianças, disponíveis na Clínica Escola. Em seguida, as mães ou os pais que acompanhavam as crianças nas terapias foram convidados a participar da pesquisa e, mediante aceitação, foram agendadas as entrevistas. Foram identificados dez pais elegíveis para o estudo, dos quais dois se recusaram a participar, alegando falta de tempo para a entrevista e não apresentar interesse em participar da pesquisa.

As informaçôes foram coletadas por meio de um roteiro de entrevista semiestruturada, elaborado especificamente para este estudo, com base nas concepções de Ferland (2006) e Takatori (2003) sobre o brincar da criança com deficiência física. O roteiro abrangia questôes sociais e demográficas sobre os participantes, como a escolaridade, a renda familiar e informaçóes sobre a criança (idade, tipo de deficiência) a fim de caracterizar a amostra estudada, além de questôes que envolviam a percepção dos pais sobre o brincar de seus filhos, tais como: se eles consideravam o brincar importante; se percebiam quando os filhos queriam brincar; com quem e como as crianças brincavam, e o que eles consideravam como fator que dificultava ou facilitava o brincar de seus filhos.

As entrevistas foram registradas em gravador de voz e eram iniciadas após a leitura e assinatura do Termo de Consentimento Livre e Esclarecido - TCLE pelo participante. As entrevistas foram transcritas e, em seguida, analisadas a partir das categorias que emergiram nos discursos dos pais, utilizando-se a técnica de análise de conteúdo (BARDIN, 2011).

Todos - pais e mães que participaram da entrevista - foram esclarecidos a respeito dos objetivos da investigação e participaram de forma voluntária. A identidade dos sujeitos da pesquisa foi mantida em sigilo, sendo utilizados os termos Máe 1, 2, 3, [...] e Pai 1 e 2, para identificação dos participantes da pesquisa. Os filhos foram identificados pelas letras iniciais de seus nomes.

\section{Resultados e Discussão}

Participaram deste estudo seis mães e dois pais. As Tabelas 1 e 2 apresentam a caracterização dos participantes e de seus respectivos filhos. Na Tabela 1, observa-se que as mães são as principais parceiras no cuidado das crianças com deficiência física atendidas na Clínica Escola de Terapia Ocupacional e representam $75 \%$ dos pais participantes da pesquisa. A maior parte dos entrevistados tinha renda de dois salários mínimos ou mais $(62,5 \%)$ e tinha como nível de escolaridade o ensino superior completo (62,5\%).

$\mathrm{Na}$ Tabela 2, nota-se que o diagnóstico mais frequente das crianças é paralisia cerebral, sendo $75 \%$ dos casos, e a faixa etária das mesmas é de 2 a 9 anos.

Nas análises das entrevistas, foram identificados cinco núcleos temáticos que possibilitaram compreender a percepção dos pais sobre o brincar no cotidiano de crianças com deficiência física, quais sejam: o brincar como meio da criança com deficiência física desenvolver-se; as características do brincar; comportamentos que indicam que a 
Tabela 1. Caracterização dos participantes (idade, escolaridade, renda).

\begin{tabular}{cccc}
\hline Participantes & Idade & Escolaridade & Renda \\
\hline Mãe 1 & $\begin{array}{c}21 \\
\text { anos }\end{array}$ & $\begin{array}{c}\text { Segundo Grau } \\
\text { Completo }\end{array}$ & $\begin{array}{c}\text { 1 Salário } \\
\text { Mínimo }\end{array}$ \\
\hline Mãe 2 & $\begin{array}{c}35 \\
\text { anos }\end{array}$ & $\begin{array}{c}\text { Segundo Grau } \\
\text { Completo }\end{array}$ & $\begin{array}{c}\text { 2 Salários } \\
\text { Mínimos }\end{array}$ \\
Mãe 3 & $\begin{array}{c}\text { anos } \\
\text { Completo }\end{array}$ & $\begin{array}{c}\text { Mínimos e } \\
\text { meio }\end{array}$ \\
\hline Mãe 4 & $\begin{array}{c}\text { Superior } \\
\text { anos }\end{array}$ & $\begin{array}{c}\text { Superior } \\
\text { Completo }\end{array}$ & $\begin{array}{c}\text { 4-5 } \\
\text { Salários } \\
\text { Mínimos }\end{array}$ \\
\hline Mãe 5 & $\begin{array}{c}\text { anos } \\
\text { andários }\end{array}$ & $\begin{array}{c}\text { Superior } \\
\text { Completo }\end{array}$ & $\begin{array}{c}\text { 1 Salário } \\
\text { Mínimo }\end{array}$ \\
\hline Mãe 6 & $\begin{array}{c}44 \\
\text { anos }\end{array}$ & $\begin{array}{c}\text { Superior } \\
\text { Completo }\end{array}$ & $\begin{array}{c}\text { 2 Salários } \\
\text { Mínimos }\end{array}$ \\
\hline Pai 1 & $\begin{array}{c}43 \\
\text { anos }\end{array}$ & $\begin{array}{c}\text { Primeiro Grau } \\
\text { Incompleto }\end{array}$ & $\begin{array}{c}\text { 2 Salários } \\
\text { mínimos }\end{array}$ \\
\hline Pai 2 & $\begin{array}{c}\text { 37 } \\
\text { anos }\end{array}$ & $\begin{array}{c}\text { Superior } \\
\text { Completo }\end{array}$ & $\begin{array}{c}\text { Sem Renda } \\
\text { Fixa }\end{array}$ \\
\hline
\end{tabular}

Tabela 2. Caracterização dos filhos dos participantes (idade, tipo de deficiência física).

\begin{tabular}{lll}
\hline \multicolumn{1}{c}{ Crianças } & $\begin{array}{c}\text { Idade da } \\
\text { criança }\end{array}$ & Tipo de Deficiência \\
\hline $\begin{array}{l}\text { Filho Mãe } 1 \\
\text { (P.) }\end{array}$ & 5 anos & $\begin{array}{l}\text { Paralisia Cerebral - } \\
\text { Diparesia Espástica }\end{array}$ \\
\hline $\begin{array}{l}\text { Filho Mãe } 2 \\
\text { (L.) }\end{array}$ & $\begin{array}{l}4 \text { anos e } \\
11 \text { meses }\end{array}$ & $\begin{array}{l}\text { Paralisia Cerebral - } \\
\text { Tetraparesia }\end{array}$ \\
\hline $\begin{array}{l}\text { Filho Mãe } 3 \\
\text { (M.F.) }\end{array}$ & $\begin{array}{l}2 \text { anos e } \\
1 \text { mês }\end{array}$ & $\begin{array}{l}\text { Paralisia Braquial } \\
\text { Obstétrica }\end{array}$ \\
\hline $\begin{array}{l}\text { Filho Mãe } 4 \\
\text { (L.C.) }\end{array}$ & 4 anos & $\begin{array}{l}\text { Paralisia cerebral - } \\
\text { Hemiparesia }\end{array}$ \\
\hline $\begin{array}{l}\text { Filho Mãe } 5 \\
\text { (M.H.) }\end{array}$ & 6 anos & $\begin{array}{l}\text { Paralisia Cerebral - } \\
\text { Tetraparesia }\end{array}$ \\
\hline $\begin{array}{l}\text { Filho Mãe } 6 \\
\text { (A.P.) }\end{array}$ & 9 anos & $\begin{array}{l}\text { Paralisia Cerebral - } \\
\text { Diparesia Espástica }\end{array}$ \\
\hline $\begin{array}{l}\text { Filho Pai 1 } \\
\text { (D.) }\end{array}$ & 6 anos & $\begin{array}{l}\text { Paralisia Cerebral - } \\
\text { Tetraparesia }\end{array}$ \\
\hline $\begin{array}{l}\text { Filho Pai 2 } \\
\text { (J.L.) }\end{array}$ & 3 anos & $\begin{array}{l}\text { AVE - Hemiplegia lado } \\
\text { direito }\end{array}$ \\
\hline
\end{tabular}

criança quer brincar; dificuldades no brincar, e facilitação do brincar.

Com relaçáo ao brincar como meio da criança com deficiência física desenvolver-se (núcleo temático A), observa-se que todos os entrevistados consideram importante que seu filho brinque, pois estes relatam ser bom para o desenvolvimento da criança, para a interação e para a aprendizagem.

Brincando ele pode se desenvolver melhor né, ajuda ele (Mãe 1).
Eu acho muito importante né na vida de uma criança, porque eles desenvolvem a partir da brincadeira, né?! Tem que ter interação né? E eu acredito que para uma criança que tem paralisia cerebral eu acho que ele desenvolve cada um ao seu modo e da sua maneira e é importante a brincadeira para isso (Mãe 2).

É fundamental para toda criança e minha filha é uma criança que gosta de brincar (Mãe 3).

Acho muito importante que ela brinque, porque é bom para o desenvolvimento de um modo geral, pois o montar, o encaixar, o brincar de boneca são estímulos que toda criança precisa e principalmente ela, para ajudá-la na escola, para acompanhar um colega que tenha o desenvolvimento melhor que ela... acho fundamental o brincar (Mãe 4).

Acho importante, com certeza. É uma forma de interagir com outra criança e se desenvolver, de aprender coisas novas. É muito bom para ela (Mãe 6).

Para o próprio desenvolvimento dele (Pai 1).

A partir da consciência que nós temos da importância da brincadeira. Nós entendemos que a brincadeira é um meio que pode ajudá-lo a evoluir, a desenvolver, especialmente o lado mais necessitado dele. Então nós entendemos que a brincadeira vai ajudar muito e nossa consciência é o ponto de partida. $\dot{E}$ um universo muito interessante, muita coisa pode ser descoberta: a importância de brincar, a importância de interagir com outras crianças, a importância da disponibilidade dos pais, dessa consciência dos pais. Então acho muito importante, muito. A brincadeira é talvez a principal estratégia para que a gente possa ver a evolução (Pai 2).

Observa-se que os pais compreendem que o brincar contribui para o desenvolvimento das crianças de um modo geral e que, em particular, o brincar colabora para a evolução do tratamento da criança com deficiência.

Para Ferland (2006), o brincar constitui um meio privilegiado de interaçáo e de evolução para a criança. Assim, é um poderoso mecanismo de aprendizagem pelo qual a criança adquire conhecimento, desenvolvendo suas capacidades de raciocínio, criando e resolvendo problemas.

Através da brincadeira, a criança adquire a experiência necessária para o desenvolvimento sensorial, motor, perceptual, cognitivo, afetivo e cultural. $\mathrm{O}$ ato do brincar também facilita o processo de aprendizagem, 
já que, por meio deste, a criança explora seu corpo e seu ambiente (PEDROSO, 2013).

Apreende-se, nas falas, que os pais apresentam discursos elaborados, detalhando funçōes do brincar no universo infantil. O fato de as crianças, cujos pais participaram do estudo, estarem em terapia pode sustentar a hipótese de que há um esclarecimento sobre a importância do brincar por parte dos terapeutas ocupacionais. Isto possibilita aos pais compreender e estimular o brincar de seus filhos.

Em relação às características do brincar (núcleo temático B), observa-se que o brincar acontece no seio familiar. As crianças brincam predominantemente em casa, todos os dias, com os pais e com objetos construídos com materiais resistentes ao manuseio.

Brinca em casa, comigo e com o pai todos os dias (Mãe 1).

Brinca! Na verdade, ele brinca comigo e com o pai, porque só somos nós três. Mas, eu coloco alguns DVD, para ele interagir com a televisáo, todos os dias quando chega da creche (Mãe 2).

Brincar? Brinca comigo e com meus dois filhos, todos os dias (Pai 1).

Gosta de brincar de bola, videogame [...] (Mãe 1).

Ela gosta de brincar com massinha, brincar de pintar, de boneca, de montar, com o cavalinho (Mãe 3).

Ele brinca de carro, de boneco, de bola. Ele pega, joga de um lado [...] (Mãe 5).

Ela gosta de brinquedos de encaixe (Mãe 4).

De bola, de carrinho... essas coisas assim (Pai 1).

As falas dos pais revelam que, no cotidiano, as crianças brincam com os familiares e com objetos resistentes, os quais suportam a falta de controle de movimento das crianças. Desta forma, as experiências lúdicas são restritas em número de pessoas que partilham as brincadeiras e em estímulos sensoriais advindos de brinquedos e objetos destinados ao brincar.

Os resultados deste estudo estão de acordo com os resultados das pesquisas de Mactavish e Schleien (2004), que estudaram o brincar em famílias com crianças com deficiência e verificaram que as atividades recreativas acontecem em pequenos grupos, sendo, na maioria das vezes, entre a dupla máe-criança.

Sobre a restriçấo nas possibilidades do brincar, Takatori (2003) ressalta que as privaçóes das experiências do brincar em virtude das barreiras físicas, sociais, pessoais e ambientais podem levar à aquisição de outras incapacidades, de ordem social e emocional, chamadas de deficiências secundárias, relacionadas com as dificuldades de participação social, que podem impedir o desenvolvimento e a vida plena por aprisionar a pessoa numa rede de barreiras atitudinais.

Percebe-se que os parentes mais próximos, geralmente os pais, são os principais parceiros de brincadeira das crianças. Assim, a função do brincar para melhorar a interação social se restringe a fortalecer os vínculos familiares, não atingindo o desenvolvimento das relações sociais extrafamiliares. Por outro lado, a falta de estímulos diversificados pode prejudicar o desenvolvimento sensorial, reduzindo também a motricidade e limitando as oportunidades de brincar com os outros, comprometendo, dessa forma, o processo de socialização da criança com deficiência física.

Brown e Gordon (1987) apud Ferland (2006) estudaram os efeitos da deficiência física e apontaram que as crianças apresentam atividades menos variadas, o ritmo das brincadeiras é mais lento e que, com a idade, elas parecem mais suscetíveis ao isolamento social.

No que se refere aos comportamentos que indicam que a criança quer brincar (núcleo temático C), os pais relataram como percebem que o filho quer brincar:

Ele choraminga para sentar e eu vejo que ele quer sentar para brincar. Ai coloco ele num canto e boto os brinquedos ao redor. Quando ele tá deitado, ele chora para sair (Mãe 5).

Quando... sempre quando ele me vê, ele fica querendo brincadeira. Ele quer ir para o chão, ai o demonstrar dele é assim (Pai 1).

Pede para ajudar a montar o jogo quando não consegue, ela aponta o que quer (Mãe 4).

É possível verificar que a maior parte dos pais percebe que a criança quer brincar através da comunicação náo verbal, expressa por sons incompreensíveis, sinais e gestos. Isto é justificável pelo fato de a maioria das crianças ter diagnóstico de paralisia cerebral, que pode afetar a expressão facial e a fala. Nestes casos, a comunicação se faz através de códigos que cada criança desenvolve em sintonia com sua família (SILVA; FRICHE, 2011). Os resultados corroboram o estudo de Zaguini et al. (2012), que apontaram a expressão facial e os gestos 
como principais meios de a criança com paralisia cerebral expressar seus interesses.

Através dos discursos dos pais, é possível perceber que as crianças não iniciam o brincar sozinhas. Considerando-se que o brincar é um comportamento espontâneo, Takata (1974) alega que as crianças com deficiência física têm poucas chances de iniciar uma brincadeira com independência e dependem da sensibilidade dos pais para perceberem que elas querem brincar. Assim, é imprescindível que os pais estejam conscientes da importância do brincar como potencializador da ação da criança sobre o meio e da interação social.

Em relação aos fatores que dificulta o brincar (núcleo temático D), observou-se que os entrevistados percebem que o prejuízo na motricidade interfere negativamente no brincar da criança.

Brincar como outras crianças, que vamos dizer assim que não tem $P C$, sim, né. Porque ele tem a limitação dele, né. Mas ele brinca ao seu modo, do seu jeitinho (Mãe 2).

Assim... em algumas coisas, né. O pula-pula, por exemplo, ela não tem o equilíbrio, assim para pular, então quando ela entra com alguma outra criança da mesma idade que já sabe pular, ela sempre fica caindo. Mas de uns dias para cá ela já está conseguindo melhor (Mãe 3).

Eu acho que tem por conta do problema dele. Ele não se interessava para brincar, nem abria as mãos e olha como ele já tá! Ele já pega na bola ou em alguma coisa [...] Não brinca assim como uma criança normal, mas já pega para brincar [...] Ele leva na boca (Mãe 5).

A maior dificuldade dela é a locomoção, mas o resto ela brinca de tudo (Mãe 6).

Por causa do problema dele (Mãe 7).

Os pais percebem que os problemas da motricidade restringem as oportunidades de seus filhos iniciarem a brincadeira e de brincarem com os outros, atribuindo a estes problemas a maior causa pela qual as crianças têm prejuízos no brincar:

A locomoção dele, a motora dele e a atenção de $L$ (Mãe 2).

Se for uma brincadeira de bola, por exemplo, que tenha que jogar de um para o outro, ela vai ter dificuldade por conta do braço direito que tem pouco movimento. Não tem movimento nem rápido nem lento na verdade, ela não consegue agarrar uma bola, se for uma brincadeira para usar as duas mãos, ai sim a dificuldade dela vai ser grande (Mãe 4).

A locomoção, só a locomoção que dificulta em algumas brincadeiras (Mãe 6).

É a parte motora dele (Pai 1).

Como falei apenas algumas brincadeiras são dificeis, por conta do lado necessitado dele (Pai 2).

De acordo com Martini (2010), as limitaçôes inerentes à deficiência física podem reduzir a capacidade de locomoção, de manipulação dos objetos e de exploração pelo sujeito, o que, por sua vez, pode reduzir o potencial da criança em vivenciar facilmente uma brincadeira. Quanto maior o dano, menos a criança manifesta capacidades lúdicas, e quanto mais a criança tem dificuldade em se locomover, menor é sua capacidade de brincar (FERLAND, 2006).

No que se refere ao modo como os pais ajudam ou facilitam o brincar (núcleo temático E), observou-se que os pais são os grandes facilitadores do brincar de seus filhos, na medida em que eles promovem o brincar das crianças, muitas vezes usando o seu próprio corpo ou fazendo pela criança.

O que ele não consegue fazer ou eu ajudo ou eu faço (Mãe 1).

Eu estimulo com cores, com objetos, dizendo as cores, falando: pegue aqui L., ó L. o vermelho, olha o vermelho, pega aqui L. nos objetos (Mãe 2).

Os brinquedos que ela tem, por exemplo, o de montar mesmo, eu sempre incentivo ela a pegar com a outra mão, os brinquedos que precisa pegar com as duas mãos ao mesmo tempo, também eu incentivo. Ela não deixa de brincar de nada por conta do problema dela (Máe 3).

Nesse caso eu vou para perto, eu seguro o cotovelo, tento ajudar ela a segurar a bola e a jogar com as duas mãos. Mas a maioria das brincadeiras que ela participa dá para ela brincar usando o braço esquerdo. Só quando ela precisa mesmo, ela consegue empurrar com o braço direito e com o esquerdo para ajudar em algum movimento (Mãe 4).

Vou lá, pego os brinquedos, coloco no colo dele que é para ele sentir que tem algo e brincar (Mãe 5).

Observa-se que os pais estấo preocupados em estimular o brincar e, para isto, desenvolvem modos de compensar as dificuldades das crianças. Porém, convém destacar que a criança, em seu cotidiano, precisa brincar de forma independente 
dos pais, mesmo apresentando comprometimento físico. O adulto deve, sempre que possível, esperar a criança realizar suas atividades e brincadeiras, em vez de antecipá-las, evitando assim fazer tudo pelas crianças e adiantar-lhes as situaçôes (VIEIRA, 2009).

Segundo Piaget (1997), a capacidade de explorar fisicamente os objetos faz com que a pessoa classifique e estabeleça uma ordem entre estes. Dessa forma, a criança com deficiência física tem dificuldade de construir esquemas para executar certas atividades em função de suas dificuldades motoras, sensoriais e cognitivas, prejudicando grandemente o brincar.

Apesar de as crianças apresentarem limitaçóes físicas e de estarem em acompanhamento com a terapia ocupacional, nenhum pai relatou o uso de técnica ou equipamento adaptado para facilitar o brincar.

Em resumo, o estudo sugere que as crianças com deficiência física apresentam restrição na atividade do brincar devido ao comprometimento motor, o que, por sua vez, limita não só as possibilidades de brincadeiras como também de parceiros para brincar. As crianças partilham a brincadeira apenas com familiares e utilizam materiais resistentes ao manuseio que nem sempre favorecem o desenvolvimento sensorial.

Neste contexto, cabe aos profissionais de saúde e educação colaborarem para a criança com deficiência física brincar, instrumentalizando a família e a criança, a fim de superar os obstáculos impostos pela deficiência. Os profissionais devem compreender que restringir o brincar da criança é restringir a participação social da mesma e que isto leva a outras dificuldades, impactando negativamente no desenvolvimento da pessoa com deficiência.

\section{Conclusão}

Após análise e reflexões, foi possível compreender que os pais percebem a importância do brincar para o desenvolvimento de seus filhos com deficiência física, inclusive fazendo relaçóes entre o ato de brincar, a aprendizagem e a interação social.

Os pais atribuem às alteraçôes de movimento as principais causas do prejuízo na atividade do brincar e, para compensar estas alterações, utilizam seus corpos como ferramenta para a criança conseguir brincar.

Neste contexto, o estudo sugere que profissionais que acompanham as crianças com deficiência física desenvolvam programas e/ou estratégias que colaborem com os pais para a efetivaçáo e a ampliação do repertório do brincar de seus filhos, a fim de facilitar o desenvolvimento da autonomia da criança e a sua participação social.

\section{Referências}

BARDIN, L. Análise de conterido. Lisboa: Edições 70, 2011.

FERLAND, F. O modelo lúdico: o brincar, a criança com deficiência física e a terapia ocupacional. São Paulo: Editora ROCA, 2006.

LORENZINI, M. V. Brincando a brincadeira com a criança deficiente: novos rumos terapêuticos. São Paulo: Manole, 2002.

MACTAVISH, J. B.; SCHLEIEN, S. J. Re-injecting spontaneity and balance in family life: parents' perspectives on recreation in families that include children with developmental disability. Journal of Intellectual Disability Research, Oxford, v. 48, n. 2, p. 123-141, 2004.

MARTINI, G. O brincar na Clínica de Terapia Ocupacional com crianças com deficiência física: relato de um caso. Revista CETO, São Paulo, n. 12, p. 27-31, 2010. Disponível em: <http://www.ceto.pro.br/revistas/12/12-05.pdf.>. Acesso em: 06 fev. 2015.

MISSUANA, C.; POLLOCK, N. Play deprivation in children with physical disabilities: The role of the occupational therapist in preventing secondary disability. American Journal of Occupational Therapy, Boston, v. 45, n. 10, p. 882-888, 1991.

PEDROSO, M. C. S. A Função do Brincar para a Criança com Deficiência. Revista Científica da FHO UNIARARAS, Araras, v. 1, n. 2, p. 82-925, 2013. Disponível em: $<$ http://www.uniararas.br/revistacientifica/_documentos/art.10-008-013.pdf.>. Acesso em: 15 mar. 2015.

PIAGET, J. A equilibração das estruturas cognitivas: problema central de desenvolvimento. Rio de Janeiro: Vozes, 1997.

REZENDE, M. B. O brincar e a intervençáo da terapia ocupacional. In: DRUMMOND, A. F.; REZENDE, M. B. Intervençôes da Terapia Ocupacional. Minas Gerais: UFMG, 2008. p. 27-44.

ROSE, J. C. C.; GIL, M. S. C. A. Regras e contingências sociais na brincadeira de crianças. In: BRANDÂO, M. Z. S. et al. Sobre comportamento e cognição: a história e os avanços, a seleção por consequência em ação. Santo André: ESETec Editores Associados, 2003. p. 383-389.

SILVA, C. M.; FRICHE, A. A. L. Fonoaudiologia em paralisia cerebral. In: CURY, V. C. R.; BRANDÃO, M. B. Reabilitação em paralisia cerebral. Rio de Janeiro: Medbook, 2011. p. 31-43.

SILVA, C. C. B.; PONTES, F. V. A utilização do brincar nas práticas de terapeutas ocupacionais da Baixada Santista. Revista de Terapia Ocupacional da Universidade de São Paulo, São Paulo, v. 24, n. 3, p. 226-232, 2013. 
TAKATA, N. Play as a prescription. In: REILLY, D. M. (Dir.). Plays as exploratory learning. Beverly Hills: Sage, 1974. p. 209-246.

TAKATORI, M.; BOMTEMPO, E.; BENETTON, M. J. O brincar e a criança com deficiência física: a construção inicial de uma história em Terapia Ocupacional. Cadernos de Terapia Ocupacional da UFSCar, São Carlos, v. 9, n. 2, p. 91-105, 2001. Disponível em: <http://www. cadernosdeterapiaocupacional.ufscar.br/index.php/cadernos/article/view/227/181>. Acesso em: 15 out. 2014.

TAKATORI, M. O brincar no cotidiano da criança com deficiência fisica: reflexos sobre a clínica da Terapia Ocupacional. São Paulo: Sprint, 2003.
VIEIRA, A. L. M. Autoridade e autonomia: uma relação entre a criança e a família no contexto infantil. Revista Iberoamericana de Educación, Espanha, v. 45, n. 9, p. 1-10, 2009. Disponível em: <http://www.rieoei.org/ deloslectores/2964Morais.pdf.>. Acesso em: 15 mar. 2015.

ZAGUINI, C. G. S. et al. Avaliação do comportamento lúdico da criança com paralisia cerebral e da percepçáo de seus cuidadores. Acta Fisiatrica, São Paulo, v. 8, n. 4, p. 187-191, 2012. Disponível em: <http://www.actafisiatrica.org.br/detalhe_artigo.asp?id=13\#.>. Acesso em: 20 set. 2014.

\section{Contribuição dos Autores}

Daniele da Silva Souza foi responsável pela concepção e redação do texto. Brenda Antunes de Figueiredo foi responsável pela organizaçáo das fontes de dados e redação do texto. Ângela Cristina Dornelas da Silva foi responsável pela orientação em todas as fases e pela revisão final. Todos os autores aprovaram a versão final do texto.

\section{Notas}

${ }^{1}$ O estudo foi aprovada pelo Comitê de Ética em Pesquisa (CEP) do Centro de Ciências da Saúde (CCS) da Universidade Federal da Paraíba (UFPB), com CAAE n 31037514.0.0000.5188. 